\title{
Ezrin-Dependent Promotion of Glioma Cell Clonogenicity, Motility, and Invasion Mediated by BCL-2 and Transforming Growth Factor- $\boldsymbol{\beta}_{2}$
}

\author{
Wolfgang Wick, ${ }^{1}$ Cornelia Grimmel, ${ }^{1}$ Christine Wild-Bode, ${ }^{1}$ Michael Platten, ${ }^{1}$ Monique Arpin, ${ }^{2}$ and \\ Michael Weller ${ }^{1}$ \\ ${ }^{1}$ Laboratory of Molecular Neuro-Oncology, Department of Neurology, University of Tübingen, School of Medicine, \\ Tübingen, Germany, and 2Laboratoire de Morphogenese et Signalisation Cellulaires, Unité Mixte de Recherche, 144 \\ Centre National de la Recherche Scientifique/Institut Curie, 75248 Paris Cedex 05, France
}

Ezrin belongs to the ezrin-radixin-moesin family proteins, which cross-link actin cytoskeleton and plasma membrane. Malignant glioma cells are paradigmatic for their strong migratory and invasive properties. Here, we report that the expression of dominant-negative ezrins inhibits clonogenicity, migration, and invasiveness of human malignant glioma cells. Furthermore, dominant-negative ezrins block hepatocyte growth factor (HGF)-mediated stimulation of clonogenicity and migration, without altering HGF-induced protein kinase B/Akt and focal adhesion kinase phosphorylation. Glioma cells expressing dominant-negative ezrins exhibit a shift of the BCL-2/ BAX rheostat toward apoptosis, reduced $\alpha_{\mathrm{V}} \beta_{3}$ integrin expression and reduced matrix metalloproteinase (MMP) expression and activity. These changes are associated with a dramatic loss of transforming growth factor $\beta_{2}$ (TGF- $\beta_{2}$ ) release. Exogenous supplementation of TGF- $\beta_{2}$ overcomes the inhibitory effects of dominant-negative ezrins on migration and clonogenicity. A neutralizing TGF- $\beta_{2}$ antibody mimics the effects of dominantnegative ezrins on clonogenicity and migration. Exogenous HGF markedly induces TGF $-\beta_{2}$ protein levels, and a neutralizing TGF- $\beta_{2}$ antibody abolishes the HGF-mediated increase in glioma cell motility. Finally, TGF- $\beta_{2}$ does not modulate BCL-2 or BAX expression, but BCL-2 gene transfer increases the levels of latent and active TGF- $\beta_{2}$. Intracranial xenografts of U87MG glioma cells transfected with the dominant-negative ezrins in athymic mice grow to significantly smaller volumes, and the median survival of these mice is $50 \mathrm{~d}$ compared with $28 \mathrm{~d}$ in the control group. These data define a novel pathway for HGFinduced glioma cell migration and invasion, which requires ezrin, changes in the BCL-2/BAX rheostat, and the induction of TGF- $\beta_{2}$ expression in vitro, and underscore the important role of HGF signaling in vivo.

Key words: brain tumor; ERM proteins; motility; TGF- $\beta$; BCL-2; metalloproteinases; HGF; athymic mice
Cellular migration is a central process during embryogenesis and cancerogenesis. Some cytokines such as epidermal growth factor (EGF), hepatocyte growth factor (HGF), or transforming growth factor $\beta$ (TGF- $\beta$ ) promote cell migration in a cell type- and context-dependent manner by triggering distinct intracellular signaling cascades (Lund-Johansen et al., 1990; Laterra et al., 1997). Migration is an integral component of tumor cell invasion. Invasion of cells into surrounding tissue is a multistep action that requires changes in cell-cell contacts, e.g., cadherins or the hyaluronic acid receptor CD44 (Hiscox and Jiang, 1999; Bourguignon et al., 2000), cell-substrate interactions, with integrins as predominant receptors mediating cell motility on various substrates and penetration of membranes (Kikkawa et al., 2000), and degradation of extracellular matrix by matrix metalloproteinases (MMPs) (Deryugina et al., 1998). Several studies have confirmed interactions of integrins expressed on glioma cells with the extracellular matrix and the activity of MMP as prerequisites for the migration and invasion of glioma cells (Deryugina et al., 1997; Goldbrunner et al., 1998). Blocking experiments have revealed

Received Sept. 18, 2000; revised March 1, 2001; accepted March 5, 2001.

This work was supported by Grant 99.012.1 from the Wilhelm Sander-Foundation to W.W. and M.W. C.W.B. is a scholar of the state of Baden-Württemberg.

Correspondence should be addressed to Dr. Wolfgang Wick, Department of Neurology, University of Tübingen, School of Medicine, Hoppe-Seyler-Strasse 3, D-72076 Tübingen, Germany. E-mail: wolfgang.wick@uni-tuebingen.de.

Copyright (C) 2001 Society for Neuroscience 0270-6474/01/213360-09\$15.00/0 the urokinase-type plasminogen activator (UPA) receptor to be a putative positive upstream regulator of MMP activity (Mohan et al., 1999). Furthermore, a role of various intracellular signaling pathways, including phospholipase phosphatidylinositol (PI) 3-kinase, mitogen-activated protein (MAP) kinase, and actin cytoskeleton-related events has been defined (Trusolino et al., 2000). For instance, HGF-induced migration of kidney-derived epithelial cells depends on ezrin, a member of the ezrin-radixinmoesin (ERM) protein family (Crepaldi et al., 1997). These proteins function as cross-linkers between actin cytoskeleton and plasma membrane, are necessary for cell-cell and cell-substrate adhesions, and are regulated by tyrosine phosphorylation in response to growth factors such as HGF, epidermal growth factor, or platelet-derived growth factor. Ezrin may signal survival through a cascade involving PI-3 kinase and the serine-threonine kinase, protein kinase $\mathrm{B} / \mathrm{Akt}(\mathrm{PKB} / \mathrm{Akt})$, in a morphogenesis assay of LLC-PK1 cells (Gautreau et al., 1999). Activation of this pathway requires phosphorylation of ezrin at Tyr-353, and LLCPK1 cells expressing dominant-negative Y353F-ezrin undergo apoptosis when grown in a three-dimensional collagen type I matrix. Moreover, ezrin may regulate cell-cell and cell-matrix adhesion in colorectal cancer cell lines by interacting with the cell adhesion molecules E-cadherin and $\beta$-catenin (Hiscox et al., 1999).

TGF- $\beta$ constitutes a family of $25 \mathrm{kDa}$ disulfide homodimers comprised of at least three different isoforms in humans. TGF- $\beta$ 
is involved in the regulation of cell division, differentiation, and death in a large variety of cell types. We have been particularly interested in the tumor-promoting role of TGF- $\beta$ in malignant gliomas that include both immunosuppressive and promigratory activity of TGF- $\beta$ (Ständer et al., 1998; Platten et al., 2000). Glioma cells are unique in their striking property to migrate and invade normal brain, often along preformed structures such as white matter tracts and subependymal space. These features are not shared with other cancer cells that derive from other organs and are often metastatic to the brain. In the present study, we delineate a central role for ezrin in glioma cell migration and invasion and show that the anti-neoplastic effects of dominantnegative ezrin are mediated by a strong antagonism of the TGF- $\beta$ pathway.

\section{MATERIALS AND METHODS}

Reagents and cell culture. Cycloheximide (CHX) and all other chemicals were obtained from Sigma (Deisenhofen, Germany). Cytotoxic drugs were obtained from the following sources: vincristine, doxorubicin (Sigma), carmustine, teniposide (Bristol, Syracuse, NY), and cytarabine (Upjohn, Heppenheim, Germany). CD95L-containing supernatant was obtained from murine CD95L-transfected N2A murine neuroblastoma cells. Recombinant human HGF was purchased from Calbiochem (La Jolla, CA). Recombinant human TGF- $\beta_{2}$ was obtained from Sigma. The glioma cell lines used in this study have been described, their glial origin determined, and their functional phosphatase and tensin homolog deleted from chromosome 10 (PTEN) status documented (Furnari et al., 1997; Weller et al., 1998; Ishii et al., 1999; Wick et al., 1999b). For the present study, nestin and glial fibrillary acidic protein (GFAP) expression were confirmed by immunoblot analysis in all cell lines included here (data not shown). Nestin antibody (1:1000) was obtained from PharMingen (Hamburg, Germany). GFAP antibody (1:1000) was purchased from Dako (Santa Barbara, CA). Stably transfected cell lines were generated using electroporation. The neo control, F353-ezrin and nterezrin plasmids were described previously (Crepaldi et al., 1997). BCL2-transfected LN-229 cells have also been characterized (Weller et al., 1995). NIH-3T3 murine fibroblasts cells were obtained from the American Type Culture Collection (Rockville, MD). Cells were cultured in DMEM supplemented with fetal calf serum (FCS; $10 \%)$, glutamine (2 $\mathrm{mM})$, and penicillin $(100 \mathrm{IU} / \mathrm{ml}) /$ streptomycin $(100 \mu \mathrm{g} / \mathrm{ml})$. For acquisition of NIH-3T3-conditioned medium, the cells were grown in regular medium (see above) to subconfluent monolayers, washed with PBS, and incubated with serum-free DMEM for $48 \mathrm{hr}$. Supernatant was harvested and stored at $-20^{\circ} \mathrm{C}$. Polyclonal rabbit anti-ezrin antibody has been described (Crepaldi et al., 1997).

Cell death studies. Cell growth, generation times, clonogenicity, and survival were assessed by crystal violet staining. Colonies of $>50$ cells were counted at low magnification for evaluation of clonogenicity. Apoptotic cell death was measured by quantitative fluorometric assessment of DNA fragmentation, based on the separation of nuclear-associated versus soluble (fragmented) DNA by centrifugation (Wick et al., 1999a). For irradiation studies, cells were grown to $70 \%$ confluence in DMEM and trypsinized and irradiated in a $\gamma$-cell (Cs137, Gammacell 1000; Nordion, Kanata, Canada) at 1 and 3 Gray (Gy). Clonogenic cell death was assessed in six-well plates at a seeding density of 500 cells per well 3 weeks later.

Immunoblot analysis and immunoprecipitation. Immunoblot studies were performed according to standard procedures (Weller et al., 1995, 1998). The following antibodies were used at the indicated concentrations: MMP-2 (72 kDa)/MMP-9 (92 kDa), tissue inhibitor of metalloproteinases-2 (TIMP-2) (21 kDa), membrane type-1 of MMP (MT-1-MMP) (66 kDa) (2 $\mu \mathrm{g} / \mathrm{ml}$; Oncogene, Calbiochem, Schwalbach, Germany), BCL-2 (26 kDa), BAX (21 kDa), and TGF- $\beta_{1 / 2}(55 \mathrm{kDa})(2$ $\mu \mathrm{g} / \mathrm{ml}$; Santa Cruz Biotechnology, Santa Cruz, CA), anti-vesicular stomatitis virus-glycoprotein (VSVG) antibody, anti-phosphoserine antibody, and anti-phosphotyrosine antibody (1 $\mu \mathrm{g} / \mathrm{ml}$; Sigma), anti-Akt antibody (46 kDa), anti-focal adhesion kinase (FAK) antibody $(125 \mathrm{kDa})$ ( $2 \mu \mathrm{g} / \mathrm{ml}$; Transduction Laboratories, Lexington, KY), and anti-CD44 antibody (clone 2C5) (R \& D Systems, Abingdon, UK). Anti-rabbit or anti-mouse $\operatorname{IgG}$ (1:4000; Santa Cruz Biotechnology) and enhanced chemiluminescence (ECL) reagents (Amersham) were used for detec- tion. Equal protein loading was ascertained by Ponceau S staining. Immunoprecipitation of serine-phosphorylated PKB was performed as detailed elsewhere (Wick et al., 1999b).

Zymography. MMP-2 activity was analyzed as described (Wick et al., 1998). Briefly, $20 \mu \mathrm{g}$ of soluble supernatant protein was separated by $10 \%$ SDS-PAGE containing $0.1 \%$ gelatin without denaturing agents. Gels were washed twice for $30 \mathrm{~min}$ in $50 \mathrm{~mm}$ Tris- $\mathrm{HCl}, \mathrm{pH} 7.5$, and $2.5 \%$ Triton $\mathrm{X}-100$, and then incubated overnight at $37^{\circ} \mathrm{C}$ in $50 \mathrm{~mm}$ Tris- $\mathrm{HCl}$, $\mathrm{pH} 7.6,10 \mathrm{~mm} \mathrm{CaCl}, 150 \mathrm{~mm} \mathrm{NaCl}$, and $0.05 \% \mathrm{NaN}_{3}$ to allow the gelatinases to digest the gelatin structure. Gels were stained with Coomassie Brilliant Blue R-250 and destained with $90 \%$ methanol/ $\mathrm{H}_{2} \mathrm{O}(1: 1)$ and $10 \%$ glacial acetic acid. Because of gelatinolytic activity, bright bands are visible at $72 \mathrm{kDa}$ for MMP-2.

Flow cytometry. For $\alpha_{\mathrm{v}} \beta_{3}$ and $\alpha_{5} \beta_{1}$ integrin analysis, the glioma cells were treated as indicated, washed with PBS, incubated with trypsin for 30 sec at room temperature, and harvested. Five $\times 10^{-5}$ cells were incubated with $1 \mu \mathrm{g}$ each of $\alpha_{\mathrm{v}} \beta_{3}$ integrin or $\alpha_{5} \beta_{1}$ integrin mouse monoclonal antibody (Chemicon, Hof heim, Germany) or $1 \mu \mathrm{g}$ of mouse IgG isotype control antibody (Sigma) in $100 \mu \mathrm{l}$ PBS and $0.1 \%$ BSA for $30 \mathrm{~min}$ at $4^{\circ} \mathrm{C}$ protected from light. The cells were washed twice with PBS and analyzed on a FACScalibur flow cytometer using Cell Quest acquisition and analysis software (Becton Dickinson, Heidelberg, Germany). Staining intensity was quantified by calculating a specific fluorescence index (SFI), which represents the ratio of mean fluorescence obtained with specific antibody versus control antibody.

$R T$-PCR. RT-PCR of TGF- $\beta_{1 / 2}$ and actin as a housekeeping gene was performed according to standard protocols using the following primers: TGF- $\beta_{1}$ forward 5'-ACTGGTGCTGACGCCTGGC-3' and reverse 5'CCTTGCTGTACTGCGTGTCC-3'; TGF- $\beta_{2}$ forward $5^{\prime}$-CACATATGGACCAGTTC-3' and reverse 5'-AATCCGTTGTTCAGGCACTC-3'; actin forward 5'-TGTTTGAGACCTTCAACACCC -3' and reverse 5'-AGCACTGTGTTGGCGTACAG-3'.

Chemotaxis assay. Migration of malignant glioma cells through $8 \mu \mathrm{m}$ pores was assessed using a 48-well micro chemotaxis chamber (Neuro Probe, Bethesda, MD). NIH-3T3-conditioned medium (30 $\mu$ l) was pipetted into the lower wells, serving as a chemoattractant. The filter membrane was placed between the top and bottom chambers and equilibrated for $30 \mathrm{~min}$ at $37^{\circ} \mathrm{C}$. Two $\times 10^{-4}$ cells in medium alone or medium containing HGF $(10 \mathrm{ng} / \mathrm{ml})$ (Calbiochem) or TGF- $\beta_{2}(2 \mathrm{ng} / \mathrm{ml})$ (Sigma) or neutralizing TGF- $\beta_{2}$ or HGF antibody $(2 \mu \mathrm{g} / \mathrm{ml}$ ) (Sigma) were applied to the upper wells and allowed to migrate through the membrane at $37^{\circ} \mathrm{C}$ in humidified air with $5 \% \mathrm{CO}_{2}$. After $24 \mathrm{hr}$, the membrane was removed, and the nonmigrated cells were removed with a wiper blade. Migrated cells on the bottom side of the membrane were fixed in methanol and stained in thiazine and eosine solution using DiffQuick (Dade Behring AG, Düdingen, Switzerland). Quantification was done by counting five fields at $20 \times$ magnification with a microscope. Cells were counted twice by at least two independent investigators (C.G., C.W.B., W.W.). Interobserver variation was $<5 \%$.

Glioma spheroids. Multicellular glioma spheroids were cultured in 25 $\mathrm{cm}^{2}$ culture flasks base-coated with $0.75 \%$ Noble Agar (Difco Laboratories, Detroit, MI) prepared in DMEM (Pedersen et al., 1993). Briefly, $3 \times 10^{-6}$ cells were suspended in $10 \mathrm{ml}$ medium, seeded onto $0.75 \%$ agar plates, and cultured until spheroids had formed. Spheroids of $\sim 200 \mu \mathrm{m}$ diameter were selected for the experiments.

Migration assay. The radial distance of 50 randomly chosen glioma cells that had migrated from a tumor spheroid on a plastic surface was measured, and the mean was used as an index of cell migration. Spheroids were transferred individually to 96 -well plates containing $200 \mu \mathrm{l}$ of serum-free medium. Every $24 \mathrm{hr}$ for $4 \mathrm{~d}$, the radial distance of migration was determined after subtraction of the initial spheroid diameter at time 0 from the diameter of the area covered with cells migrated from the spheroid.

Confrontation assay using fetal rat brain aggregates. Fetal rat brain aggregates were obtained from 18-d-old fetuses of BD9 rats. The brains were aseptically removed and placed into a sterile tissue-culture plate containing PBS. The brain tissue was minced, washed in PBS, and dissociated by serial trypsinization. Single cell suspensions were obtained and plated into agar-coated 24-well plates at an average of the cell amount of one brain per well in $2 \mathrm{ml}$ of medium. After $48 \mathrm{hr}$, aggregates were transferred to new plates and cultured for $19 \mathrm{~d}$. Aggregates of $\sim 200$ $\mu \mathrm{m}$ diameter were used for the experiments (Pedersen et al., 1993). Invasion of the glioma spheroids into fetal brain aggregates was analyzed by morphometry using the MCID digitalization system (Imaging Research, St. Catharines, Ontario, Canada). Briefly, tumor spheroids and 
rat brain aggregates were transferred in triplicate to individual wells of a 96-well plate, base-coated with agar. With the help of a sterile syringe and a microscope, tumor spheroids and fetal brain aggregates were placed in close contact to each other. Images were obtained at $24 \mathrm{hr}$ intervals.

Animal studies. Before implantation, subconfluent glioma cell cultures were trypsinized in cell culture flasks and incubated in fresh medium for reconstitution of cell surface proteins. Subsequently, the cells were washed twice with PBS, counted, and resuspended in PBS. All animal work was performed in accordance with the N IH guidelines Guide for the Care and Use of Laboratory Animals. Athymic mice (CD1 nu/nu; Charles River, Sulzfeld, Germany) were anesthetized with $7 \%$ chloral hydrate. For intracranial implantation, the mice were placed in a stereotactic fixation device (Stoelting, Wood Dale, IL). A burr hole was drilled into the skull $2 \mathrm{~mm}$ lateral to the bregma. The needle of a Hamilton (Darmstadt, Germany) syringe was introduced to a depth of $3 \mathrm{~mm}$. Five $\times 10^{-4}$ glioma cells in $4 \mu \mathrm{l}$ PBS were injected into the right striatum. The mice were observed daily and killed by an overdose of anesthetic when developing neurological symptoms. Alternatively, all mice were killed $28 \mathrm{~d}$ after the inoculation of tumor cells. Cryostat sections $(16 \mu \mathrm{m})$ were cut, air-dried, and stored at $-20^{\circ} \mathrm{C}$. For the assessment of tumor volume, cryostat sections were stained with hematoxylin and eosin and analyzed by MCID software (Imaging Research).

Statistical analysis. Quantitative data were obtained for survival, migration, invasion, $\alpha_{\mathrm{V}} \beta_{3}$ expression, for tumor volumes, and survival of human glioma xenograft-bearing athymic mice, as indicated. Experiments reported were usually performed in triplicate and repeated three times. The significance of the observed effects was evaluated by $t$ test at $p<0.05$.

\section{RESULTS}

\section{Dominant-negative ezrin inhibits the clonogenicity of glioma cells without altering their sensitivity to apoptosis}

Immunoblot analysis revealed that all 12 human glioma cell lines examined expressed ezrin protein (Fig. 1A). The dominantnegative ezrin plasmids, F353-ezrin and nter-ezrin, were transfected into four of these cell lines, LN-18, U87MG, LN-319, and LN-229. Transgene expression was verified by immunoblot analysis for the VSVG tag (Fig. 1B). Although the doubling times of the transfected cell lines did not differ significantly from control transfectants or wild-type cells ( $p>0.05$; $t$ test; data not shown), colony-forming assays revealed a marked reduction of clonogenicity in polyclonal cell lines expressing F353-ezrin or nter-ezrin (Fig. 1C). F353-ezrin has been shown to confer an apoptotic phenotype to LLC-PK1 kidney-derived epithelial cells in a tubulogenesis assay, involving an interaction of ezrin with the C-terminal SH2 domain of the p85 subunit of PI-3 kinase and phosphorylation of ezrin Tyr-353 in a cell-free assay (Gautreau et al., 1999). Because PKB/Akt is an essential component in signaling survival downstream of PI-3 kinase and because PKB/Akt modulates sensitivity to irradiation and CD95L-induced apoptosis in glioma cells after functional PTEN has been introduced into PTEN-mutant cell lines (Wick et al., 1999b), we next asked whether ezrin regulates sensitivity to apoptosis in malignant glioma cells and whether the PTEN function of the cells is relevant. Figure $1 D$ shows that glioma cell lines expressing the dominant-negative ezrin variants do not show enhanced baseline DNA fragmentation. Furthermore, they exhibit unaltered sensitivity to five different chemotherapeutic drugs, including vincristine (Fig. $1 E$ ) as well as cytarabine, teniposide, doxorubicin, and carmustine (data not shown), to irradiation at 1 or 3 Gy and to CD95L in the presence of CHX, a protein synthesis inhibitor that facilitates CD95L-induced apoptosis (Fig. 1E) (Weller et al., 1994). Thus, dominant-negative ezrin appears not to modulate PKB/Akt-dependent survival pathways in glioma cells, and
PTEN expression is not relevant in this respect because U87MG and LN-229 cells express a full PTEN protein and LN-18 and LN-319 cells harbor no functional PTEN. Accordingly, we determined that the HGF-induced increase in $\mathrm{PKB} / \mathrm{Akt}$ levels and serine phosphorylation of $\mathrm{PKB} / \mathrm{Akt}$ are unaffected in glioma cells expressing dominant-negative ezrin (Fig. $1 F$ ).

\section{Dominant-negative ezrin inhibits constitutive and HGF- enhanced migration and invasion}

Because ezrin has been characterized as an effector of HGFinduced migration in LLC-PK1 cells (Crepaldi et al., 1997) and because HGF effects on PKB were unaffected by dominant-negative ezrin in glioma cells (Fig. $1 F$ ), we next examined the consequences of dominant-negative ezrin expression on glioma cell migration in the absence or presence of HGF. As expected, exposure of neo control transfectants to HGF resulted in enhanced glioma cell migration (Fig. $2 A$, open bars). In contrast, glioma cell lines expressing the dominantnegative ezrins exhibited a striking reduction in baseline migration and were refractory to the stimulation of migration by HGF (Fig. 2A, striped and black bars). Representative filters demonstrating the inhibition of migration by nter-ezrin are depicted in Figure 2B. Moreover, dominant-negative ezrins inhibited the migration of glioma cells from preformed spheroids (Fig. $2 C$ ), inhibited invasion in a matrigel chamber assay both in the absence or presence of HGF (data not shown), and prevented the invasion of rat brain aggregates (Fig. 2D). The latter assays revealed, e.g., for LN-229 cells, complete invasion of the brain aggregate at $24 \mathrm{hr}$ by control cells, whereas little invasion was seen when the glioma cells expressed dominantnegative ezrins. To explore the role of endogenous HGF for motility, we performed filter migration assays with a neutralizing HGF antibody. There was a reduction of migration of control-transfected U87MG and LN-229 glioma cells to the same levels as achieved after expression of dominant-negative ezrins (Fig. 2E). Moreover, the HGF antibody did not further reduce migration in the cell lines expressing dominantnegative ezrins, indicating that dominant-negative ezrin virtually abrogates the effects of endogenous HGF in migration.

\section{Dominant-negative ezrins alter the BCL-2/BAX rheostat toward apoptosis and reduce $\alpha_{v} \beta_{3}$ integrin expression and MMP activity}

Because glioma cells expressing F353-ezrin or nter-ezrin displayed a less migratory and invasive phenotype (Fig. 2) and because BCL-2 family proteins (Merlo et al., 1997; Wick et al., 1998) MMP-2 (Deryugina et al., 1997), MT1-MMP (Belien et al., 1999), TIMP-2 (Brooks et al., 1996; Shofuda et al., 1998), and FAK (Chen et al., 1998) modulate migration and invasion in various cell types, we next asked whether dominant-negative ezrins had effects on these parameters. These experiments were performed in LN-229 cells. Figure $3 A$ shows that LN-229 cells expressing F353-ezrin or nter-ezrin had lower BCL-2 and BCL- $\mathrm{X}_{\mathrm{L}}$ and higher BAX levels as well as lower MMP-2, MT1MMP and especially MMP-9 levels, with TIMP-2 levels unaltered. These changes were associated with a reduction in MMP-2 activity after zymography. Despite recent evidence of interaction of HGF and the ERM family with CD44 (Hiscox and Jiang, 1997; Yonemura et al., 1999), CD44 expression determined by immunoblot analysis was not modified by expression of dominantnegative ezrin (data not shown). 
A

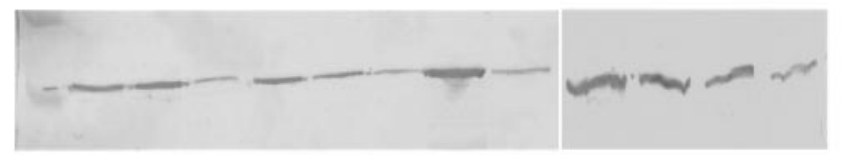

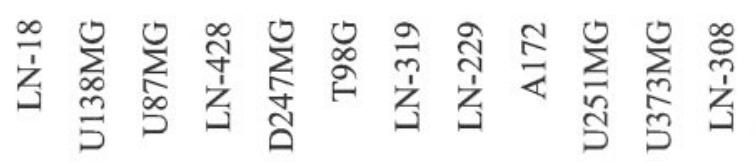

B
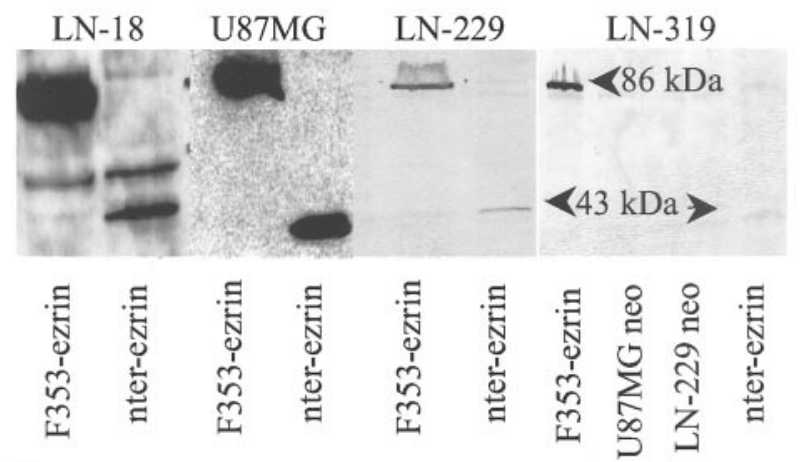

C

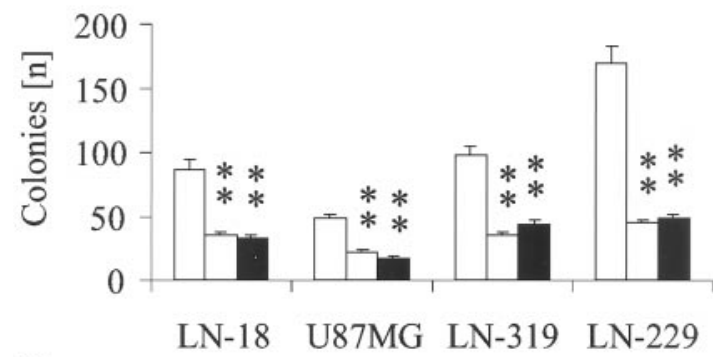

D

LN-18 U87MG LN-319 LN-229
$\mathbf{E}$
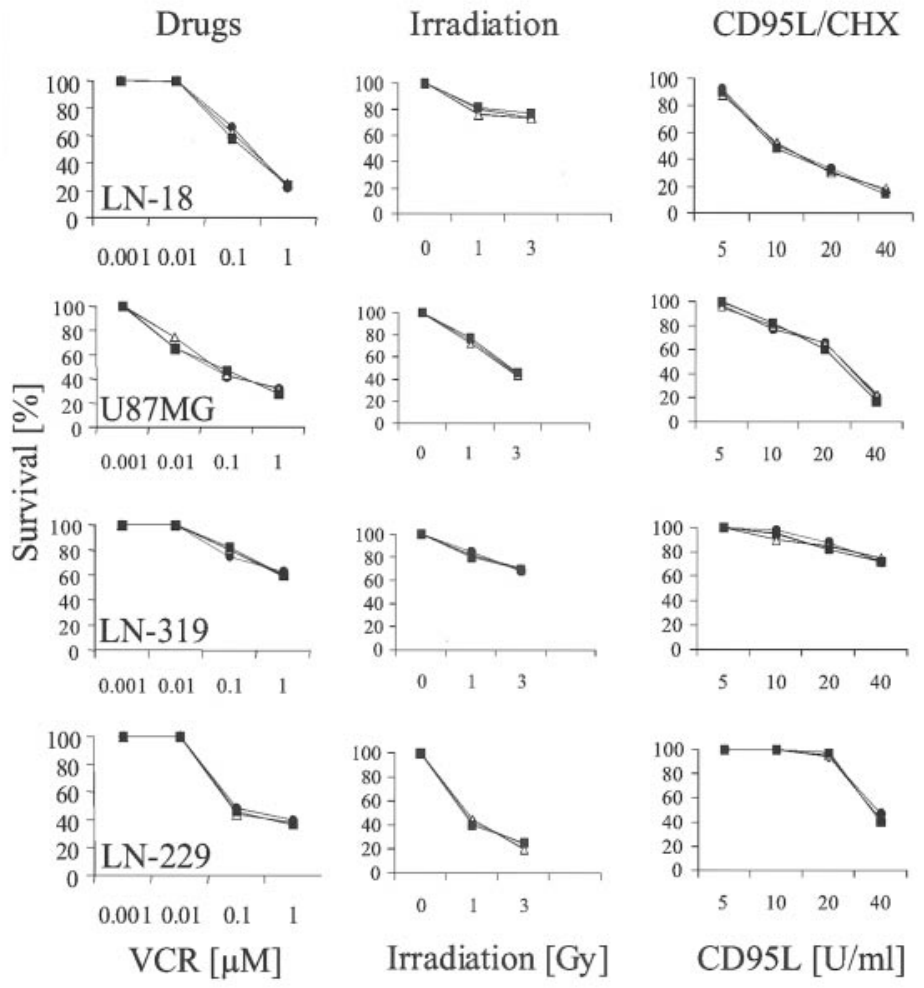

Irradiation [Gy]

F

PKB

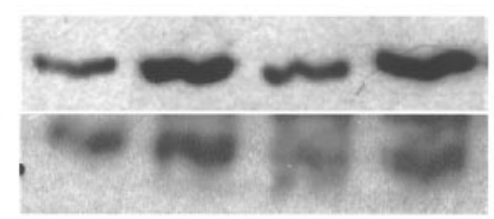

neo

nter-ezrin

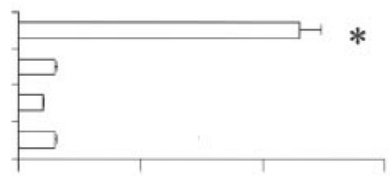

P-Ser

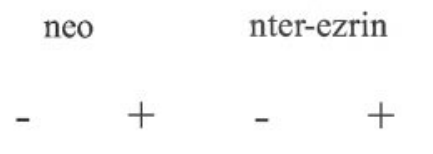

\section{$\begin{array}{llll}0 & 10 & 20 & 30\end{array}$ \\ DNA fragmentation}

Figure 1. Dominant-negative ezrin inhibits clonogenicity but modulates neither sensitivity to apoptosis nor HGF-mediated PKB/Akt stimulation. $A$, Immunoblot analysis for ezrin was performed using a polyclonal ezrin antibody. $B$, Immunoblot analysis for the VSVG-tagged $\mathrm{NH}_{2}$-terminal domain of ezrin (nter-ezrin, $43 \mathrm{kDa}$ ), and the VSVG-tagged mutant (F353-ezrin, $86 \mathrm{kDa}$ ) was performed using a VSVG antibody. C, Clonogenicity of control transfectants (open bars, left) or F353-ezrin (open bars, middle)- or nter-ezrin-expressing cells (black bars) was assessed by colony-forming assay (mean and SEM; $n=3 ; * *<<0.01 ; t$ test). $D$, Spontaneous DNA fragmentation of neo-, F353-ezrin-, or nter-ezrin-transfected LN-229 cells was assessed by DNA fluorometry (Wick et al., 1999a). As a positive control, nontransfected parental cells were treated with CD95L (50 U/ml) and CHX (10 $\mu \mathrm{g} / \mathrm{ml})$ for $16 \mathrm{hr}$ (mean percentages and SEM; $n=3 ;{ }^{*} p<0.05 ; t$ test). E, Neo ( filled circles)-, F353-ezrin ( filled squares)-, or nter-ezrin (open triangles)-transfected sublines of the LN-18, U87MG, LN-319, or LN-229 cell lines were treated with vincristine (VCR) for 72 hr (left panel), irradiated, and assessed for colony formation (middle panel), or treated with CD95L plus CHX $(10 \mu \mathrm{g} / \mathrm{ml})$ for $16 \mathrm{hr}$ (right panel) (mean percentages; $n=3$; SEM $<10 \%$ ). F, PKB was immunoprecipitated from untreated $(-)$ or $\operatorname{HGF}(10 \mathrm{ng} / \mathrm{ml}, 24 \mathrm{hr})$-treated $(+) \mathrm{LN}-229$ cells transfected with the neo control plasmid or nter-ezrin. The lysates were analyzed by SDS-PAGE and immunoblot analysis for PKB levels (top panel) and serine phosphorylation (bottom panel).

Next, we examined FAK expression levels and FAK tyrosine phosphorylation in these cells in the absence or presence of HGF (10 ng/ml). These experiments were performed because there is evidence that HGF-induced motility of MTLn3 breast carcinoma cells is mediated by FAK (Beviglia and Kramer, 1999). Interestingly, we observed increased FAK phosphorylation in response to HGF in all cell lines independent of the ezrin status (data not shown). In contrast, flow cytometry revealed a significant reduction of $\alpha_{\mathrm{V}} \beta_{3}$ integrin expression in F353-ezrin- and nter-ezrin-expressing LN-229 cells, but no such effect for $\alpha_{5} \beta_{1}$ integrin expression (Fig. 3B). The labeling intensity for $\alpha_{\mathrm{v}} \beta_{3}$ integrin, expressed as the SFI, fell from 14.9 in neo cells to 5.5 and 4.8 in F353-ezrin- and nter-ezrintransfected cells. 
$\mathbf{A}$

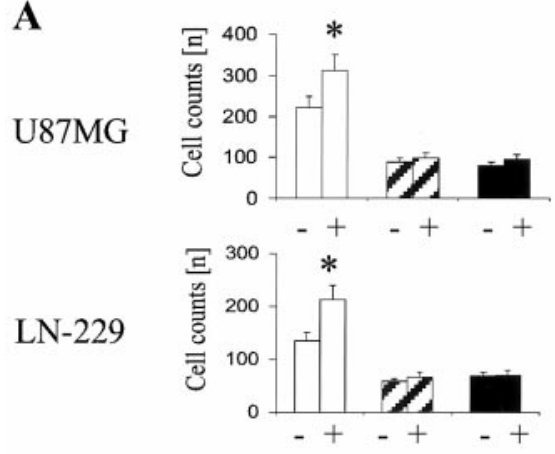

D

$0 \mathrm{~h}$

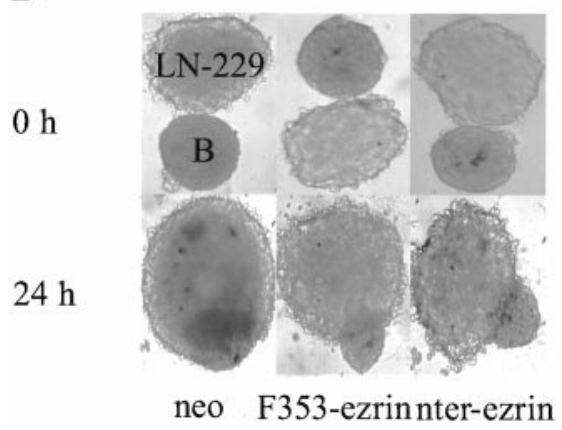

B

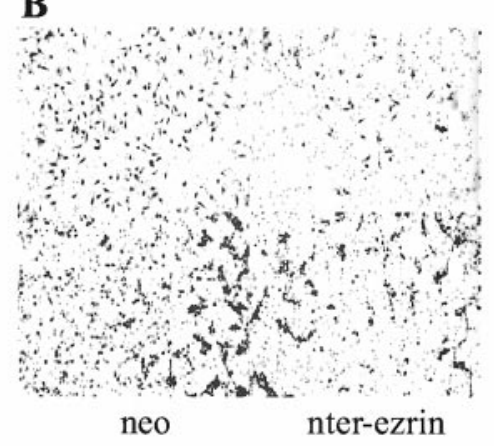

$\mathbf{E}$

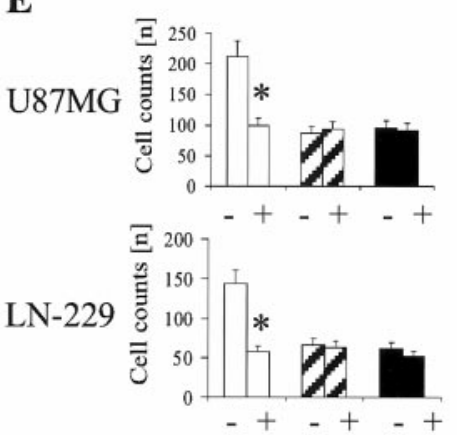

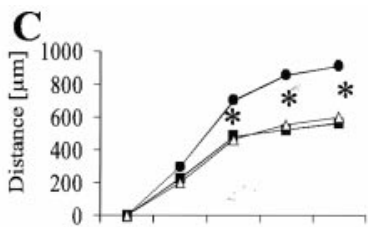

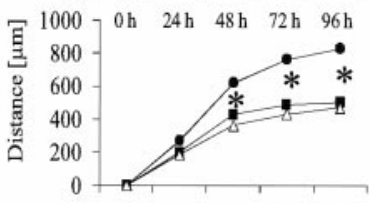

$0 \mathrm{~h} \quad 24 \mathrm{~h} \quad 48 \mathrm{~h} \quad 72 \mathrm{~h} \quad 96 \mathrm{~h}$

Figure 2. Dominant-negative ezrin reduces constitutive and HGF-induced migration and invasion. $A$, Migration was measured in the absence (-) or presence $(+)$ of HGF $(10 \mathrm{ng} / \mathrm{ml})$ in a chemotaxis chamber assay in glioma cells transfected with control plasmid (open bars), F353-ezrin (striped bars), or nter-ezrin (black bars). Migrated cells were counted in five random fields (mean and SEM; $n=3$; ${ }^{*} p<0.05 ; t$ test). Representative filters demonstrating nter-ezrin-mediated inhibition of migration are shown in $B$ (magnification, 200×). $C$, The transfected cell lines (neo, filled circles; F353-ezrin, filled squares; nter-ezrin, open triangles) were analyzed for migration from preformed spheroids. The distance in micrometers from the center of the spheroid minus the diameter of the spheroid was measured for 50 representative migrated cells (mean values; $n=3 ;{ }^{*} p<0.05 ; t$ test; SEM $<$ $10 \%) . D$, The transfected LN-229 cell lines were analyzed in confrontation assays that assess invasion of a rat brain aggregate. The images show the brain aggregate (labeled $B$ ) as smaller and the tumor spheroid (labeled LN-229) as relatively larger. $E$, Migration was measured in the absence ( - ) or presence $(+)$ of neutralizing $\alpha$-HGF-antibody $(2 \mathrm{ng} / \mathrm{ml})$ in a chemotaxis chamber assay in glioma cells transfected with control plasmid (open bars), F353-ezrin (striped bars), or nter-ezrin (black bars). Migrated cells were counted in five random fields (mean and SEM; $n=3 ;{ }^{*} p<0.05 ; t$ test).

\section{Loss of TGF- $\beta_{2}$ is responsible for the inhibition of migration and invasion in glioma cells expressing dominant-negative ezrins}

Because a neutralizing $\alpha_{\mathrm{V}} \beta_{3}$ integrin antibody inhibits migration in glioma cells and because the stimulation of migration induced by TGF- $\beta$ may involve enhanced $\alpha_{\mathrm{V}} \beta_{3}$ integrin expression (Platten et al., 2000), we went on to examine a possible role for TGF- $\beta$ in the biological effects of dominantnegative ezrins. There was a profound reduction in the release both of the mature $55 \mathrm{kDa}$ TGF- $\beta_{2}$ and TGF- $\beta_{1}$ protein and of the active $12.5 \mathrm{kDa}$ form in $\mathrm{F} 353$-ezrin- and in nter-ezrinexpressing LN-229 cells (Fig. $4 A$ ). The loss of TGF- $\beta$ protein levels appeared to be the result of decreased transcription or stabilization of TGF- $\beta$ mRNA in dominant-negative ezrinexpressing cells (Fig. 4A, bottom panels). Consistent with a key role of TGF- $\beta_{2}$ in the altered migration phenotype of glioma cells expressing dominant-negative ezrins, a neutralizing TGF- $\beta_{2}$ antibody markedly reduced migration of neo control LN-229 cells, but did not affect the residual migration of F353-ezrin and nter-ezrin transfectants (Fig. 4B). Furthermore, exogenous TGF- $\beta_{2}$ did not increase migration in control cells but reversed the anti-migratory effects of dominantnegative ezrins (Fig. 4C). These experiments demonstrated that reduction of TGF- $\beta_{2}$ synthesis mediated the inhibition of migration in dominant-negative ezrin-expressing cells.

\section{TGF- $\boldsymbol{\beta}_{\mathbf{2}}$ is a key target for HGF-controlled migration}

The next set of experiments defined the place of HGF in that signaling cascade. As expected, HGF induced TGF- $\beta_{2}$ synthesis and release, and this response was blunted by nter-ezrin (Fig. $5 A$ ). Furthermore, neutralizing TGF- $\beta_{2}$ antibody abrogated the promigratory effects of HGF (Fig. $5 B$ ), confirming that the pathway from HGF to enhanced migration involves functional ezrin and enhanced TGF- $\beta_{2}$ bioactivity. Similarly, TGF- $\beta_{2}$, but not HGF, rescued dominant-negative ezrin-induced inhibition of colony formation (Fig. 5C). Finally, we sought to determine the interrelations between two apparently crucial effects of dominantnegative ezrins, (1) alterations in BCL-2 family protein expression (Fig. 3) and (2) alterations in TGF- $\beta_{2}$ activity (Fig. 4A). First, we show that the exposure of LN-229 neo or nter-ezrin cells to TGF- $\beta_{2}$ does not modulate BCL-2 or BAX expression (Fig. $6 A$ ). Second, the analysis of BCL-2-transfected LN-229 cells, which have previously been characterized (Weller et al., 1995; Wick et al., 1998), revealed a significant increase of latent and active TGF- $\beta_{2}$ levels released into the supernatant (Fig. 6B). Similar results were obtained with TGF- $\beta_{1}$ (data not shown).

\section{Dominant-negative ezrin impairs glioma growth in vivo}

The observed reduction of clonogenicity and the antimigratory and anti-invasive effect of dominant-negative ezrin expression in vitro prompted us to examine the growth of U87MG glioma cells with dominant-negative ezrin in vivo. To this end, human 
$\mathbf{A}$

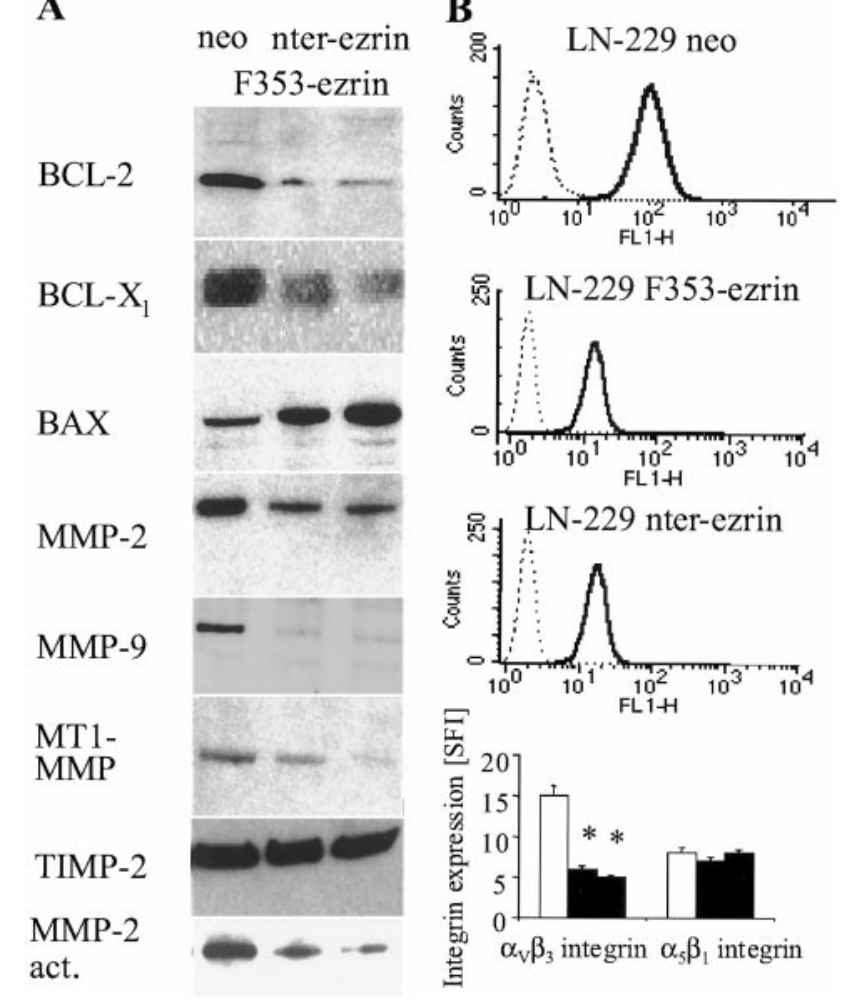

Figure 3. Dominant-negative ezrin-induced inhibition of migration and invasion: association with altered BCL-2/BAX rheostat, decreased MMP activity, and decreased $\alpha_{\mathrm{v}} \beta_{3}$ integrin expression. $A$, The levels of BCL-2, BCL-X $\mathrm{X}_{\mathrm{L}}$, and BAX in LN-229 whole-cell lysates and of MMP-2, MMP-9, MT1-MMP, and TIMP-2 in the supernatant were examined by immunoblot. MMP-2 activity in conditioned medium of neo, nter-ezrin-, and F353-ezrin-transfected LN-229 cells was examined by gelatin zymography. All blots are representative of experiments performed three times with similar results. $B, \alpha_{v} \beta_{3}$ and $\alpha_{5} \beta_{1}$ integrin expression were determined by flow cytometry. The curves for $\alpha_{\mathrm{V}} \beta_{3}$ antibody (bold line) and control antibody (dotted line) are shown. As documented in the bottom panel, there was no change in $\alpha_{5} \beta_{1}$ integrin. In the bar graph, data are expressed as mean SFI values $(n=3)$.

U87MG F353-ezrin, nter-ezrin, or neo-transfected control cells were implanted into the basal ganglia of athymic mice. Four weeks after implantation, histological analysis revealed that the tumors formed by cells expressing the dominant-negative ezrins were considerably smaller than the control tumors (Fig. 7A). The median survival of animals carrying control tumors was $28 \mathrm{~d}$, whereas animals carrying tumors expressing dominant-negative ezrins experienced a median survival of $50 \mathrm{~d}$ (Fig. $7 B)(p<0.05$; $t$ test).

\section{DISCUSSION}

Ezrin belongs to the ERM proteins that link plasma membrane receptors to the cytoskeleton. Biological functions of ERM proteins include a role in cell-cell or cell-substrate contacts, by formation of microvilli, cell-cell junctions, and membrane ruffels. They also regulate cell motility (Crepaldi et al., 1997). Recent work in this field has concentrated on the identification of ezrin binding molecules. Thus, CD44, CD43, intercellular adhesion molecule (ICAM)-2 and -3 (Algrain et al., 1993; Lesley et al., 1993), and syndecan-2 (Granés et al., 2000) have been shown to coimmunoprecipitate with ezrin.

Human malignant glioma cells exhibit specific properties to migrate and invade the normal brain, thus causing brain tissue

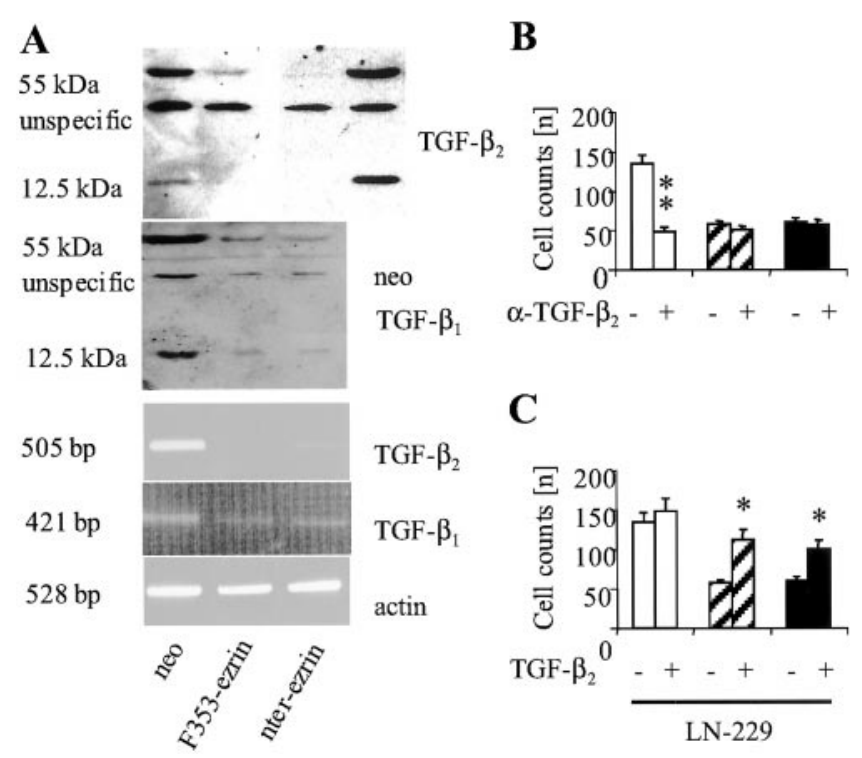

Figure 4. Inhibition of glioma cell clonogenicity, migration, and invasion by dominant-negative ezrin involves loss of TGF- $\beta_{2}$. A, TGF- $\beta_{2}$ and TGF- $\beta_{1}$ levels in the conditioned medium of neo (lanes 1 and 4 ) or F353-ezrin or nter-ezrin-transfected LN-229 cells were assessed by immunoblot. In the bottom panels, the levels of TGF- $\beta_{1}$ and TGF- $\beta_{2}$ mRNA were assessed by semiquantitative RT-PCR. $B, C$, The migration of $\mathrm{LN}-229$ sublines was measured in the absence $(-)$ or presence $(+)$ of neutralizing TGF- $\beta_{2}$ antibody $(2 \mu \mathrm{g} / \mathrm{ml})(B)$ or the absence $(-)$ or presence $(+)$ of TGF- $\beta_{2}(2 \mathrm{ng} / \mathrm{ml})(C)$ (mean and SEM; $n=3 ;{ }^{*} p<0.05$, ${ }^{* *} p<0.01$ for the effect of TGF- $\beta_{2}$ antibody in $B$ or of TGF- $\beta_{2}$ in $C$ ).

destruction and deterioration of neurological function. These migratory and invasive properties of glioma cells are not shared by nonglial cancer cells, which form mainly solid lesions when spreading to the brain. Furthermore, human glioma cells are particularly resistant to multiple apoptotic stimuli, including chemotherapy and irradiation.

In the present work, we examined the role of ezrin in the migratory and invasive phenotype of human malignant glioma cells. Using gene transfer of two different dominant-negative ezrin variants, we show that inhibition of ezrin function does not alter glioma cell proliferation under optimal conditions, that is, logarithmic growth, but results in decreased colony formation (Fig. 1C). Inhibition of ezrin function does not alter the apoptosis-resistant phenotype of malignant glioma cells, irrespective of whether cytotoxic drugs, irradiation, or a cytotoxic cytokine CD95L, are used as apoptotic stimulus, and irrespective of PTEN functional status because LN-229 and LN-18 retain wild-type PTEN function and express a functional protein, whereas U87MG and LN-319 harbor no functional PTEN (Fig. 1E) (Furnari et al., 1997; Wick et al., 1999b). Accordingly, HGFdependent stimulation of the $\mathrm{PKB} / \mathrm{Akt}$ survival pathway is unaffected by dominant-negative ezrins (Fig. $1 F$ ). These results in glioma cells contrast with previous observations in LLC-PK1 cells (Gautreau et al., 1999), indicating that the biological effects of disrupting ezrin function are cell type-specific.

In contrast to the unaltered apoptosis-resistant phenotype, all glioma cell lines expressing either variant of dominant-negative ezrin exhibit decreased migratory and invasive properties in various experimental paradigms (Fig. 2). Moreover, dominantnegative ezrin abrogated the enhanced migration of the glioma cells in response to HGF (Fig. 2E), a well established inducer of glioma cell migration (Laterra et al., 1997; Lamszus et al., 1998). 
A

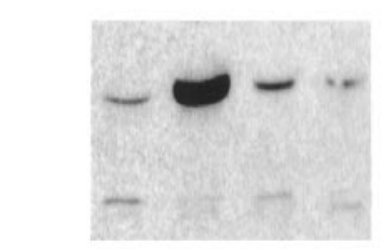

HGF $\underset{\text { neo }}{ }{ }^{+} \quad-\quad+$
B

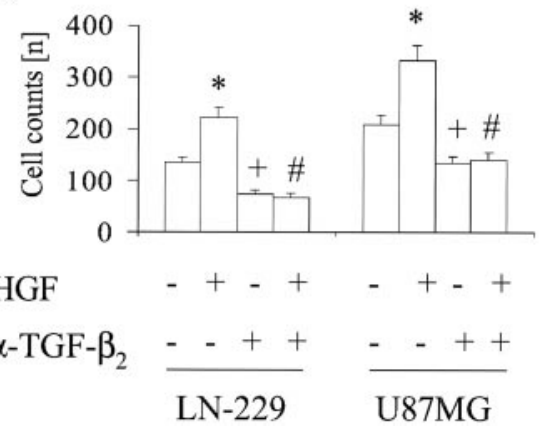

C

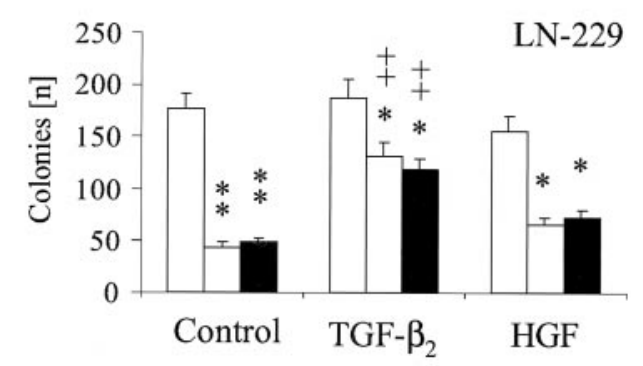

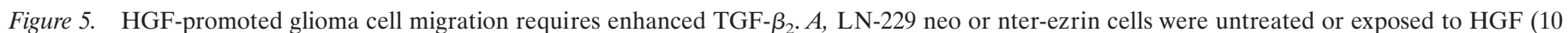

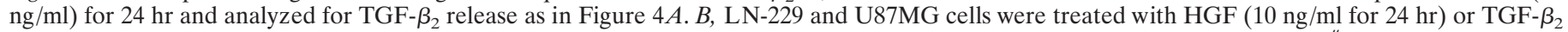

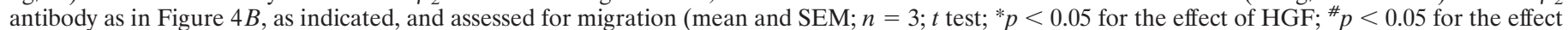

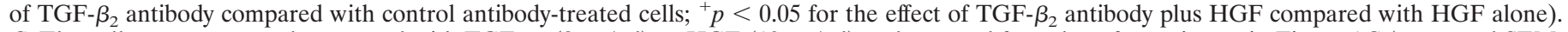

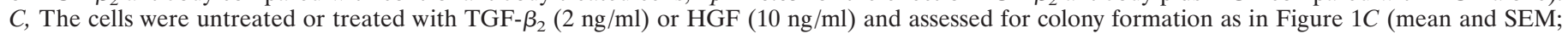

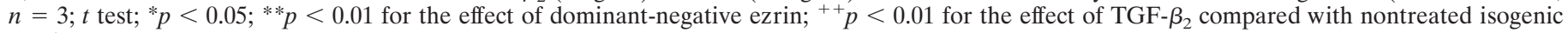
cells).

Thus, ezrin mediates some, e.g., migration, but not all, e.g., $\mathrm{PKB} /$ Akt stimulation, effects of HGF in glioma cells.

The next step was to elucidate the molecular players involved in the antimigratory and anti-invasive effect of dominant-negative ezrin expression. Because BCL-2 gene transfer has previously been shown to confer a more migratory and invasive phenotype in glioma cells (Wick et al., 1998), we hypothesized that dominant-negative ezrin expression might alter the expression patterns of BCL-2 family proteins. In fact, there was a reduction of BCL-2 and BCL- $\mathrm{X}_{\mathrm{L}}$ expression and an increase in BAX expression in dominant-negative ezrin-expressing cells (Fig. 3). Interestingly, although BCL-2 gene transfer induces resistance of glioma cells to cytotoxic drugs, irradiation, and CD95L (Weller et al., 1995), the changes of endogenous BCL-2 family protein expression observed as a consequence of dominant-negative ezrin expression (Fig. 3) did not translate into changes in vulnerability to apoptosis (Fig. 1), indicating that the expression levels achieved by plasmid transfection are rather unphysiological. Consistent with increased MMP expression after BCL-2 gene transfer (Wick et al., 1998), MMP-2, MMP-9, and MT1-MMP levels were decreased in dominant-negative ezrin-expressing glioma cells (Fig. $3 A, B$ ). Furthermore, the levels of $\alpha_{\mathrm{v}} \beta_{3}$ integrin, another important mediator of glioma cell migration (Platten et al., 2000), were reduced in these cell lines (Fig. 3D).

Because $\alpha_{\mathrm{v}} \beta_{3}$ integrin is a target of TGF- $\beta$-mediated promotion of glioma cell migration, we went on to test the hypothesis that dominant-negative ezrins affect the biological activity of TGF- $\beta$. We observed that dominant-negative ezrin-transfected glioma cells release much less TGF- $\beta$ into the cell culture supernatant than control-transfected cells (Fig. 5). Consistent with a central role of TGF- $\beta$ loss in the dominant-negative ezrin phenotype of impaired migration and invasion, a neutralizing TGF- $\beta$ antibody inhibits migration in control cells, but not in dominantnegative ezrin-transfected cells, confirming that the residual endogenous TGF- $\beta$ released by ezrin-transfected cells plays no role in the residual migratory potential of these cells. Conversely, exogenous TGF- $\beta$ rescues part of the inhibitory effect of dominant-negative ezrin in migration. These observations identify loss of TGF- $\beta$ as a necessary and sufficient consequence of dominant-negative ezrin expression, which explains the phenotype of reduced migration and invasion.

Having identified this pathway leading from disrupted ezrin function to loss of TGF- $\beta$ and impaired migration, we investigated whether HGF feeds into the same cascade when promoting glioma cell migration. The experiments summarized in Figure 5 show this to be the case. HGF promotes TGF- $\beta$ release, and this response is blunted by dominant-negative ezrin (Fig. 5A). Furthermore, the migration response to HGF is abrogated by a neutralizing TGF- $\beta_{2}$ antibody (Fig. $5 B$ ). Interestingly, TGF- $\beta$ may also be involved in the deficient colony formation of dominant-negative ezrin-expressing glioma cells because TGF$\beta_{2}$, but not HGF, partially restored colony formation in these cells. Finally, we determined a possible interrelation between the changes in BCL-2 family protein expression (Fig. 3) and the changes in TGF- $\beta$ synthesis (Fig. 4) in glioma cells engineered to express dominant-negative ezrin. Exogenous TGF- $\beta$ did not alter BCL-2 family protein expression, whereas BCL-2 gene transfer promoted TGF- $\beta$ release (Fig. 6).

Given the reduced colony-forming activity of glioma cells expressing dominant-negative ezrin reported here (Fig. $1 C$ ) and the growth-promoting effect of HGF on intracranial 9L rat gliosarcomas in vivo (Laterra et al., 1997), we demonstrated that dominant-negative ezrins diminished the growth of human U87MG glioma xenografts in nude mice (Fig. 7 $A$ ). Consequently, mice expressing the dominant-negative ezrins lived markedly longer than control animals (Fig. 7B). This is in line with recently
$\mathbf{A}$

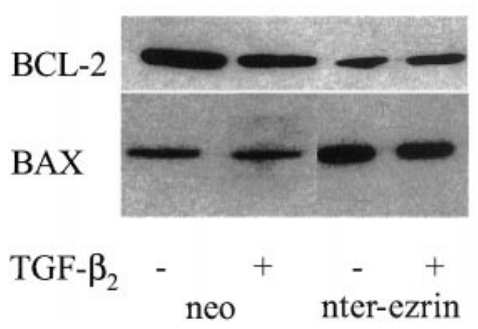

B

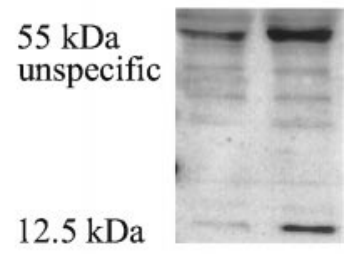

neo BCL-2
Figure 6. Increased TGF- $\beta_{2}$ release by BCL-2-transfected glioma cells. $A$, The levels of BCL-2 and BAX were measured in whole-cell lysates of LN-229 neo and nter-ezrin cells after no treatment $(-)$ or exposure to TGF- $\beta_{2}(2 \mathrm{ng} / \mathrm{ml})$ for $24 \mathrm{hr}(+)$ by immunoblot. $B$, Released TGF- $\beta_{2}$ was detected in the conditioned medium of LN-229 neo or BCL-2 cells by immunoblot analysis as in Figure $4 A$. 
$\mathbf{A}$

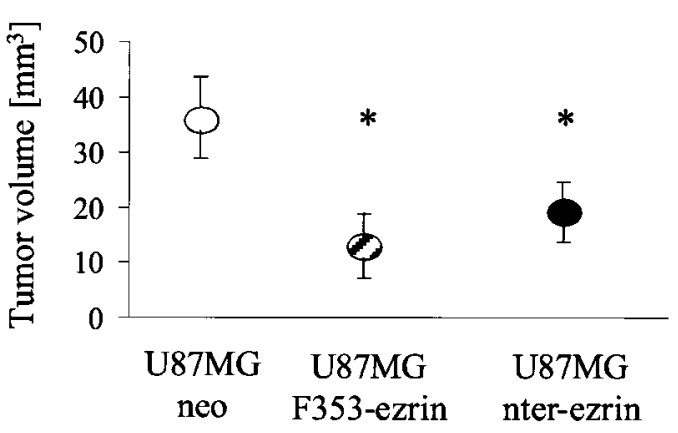

B

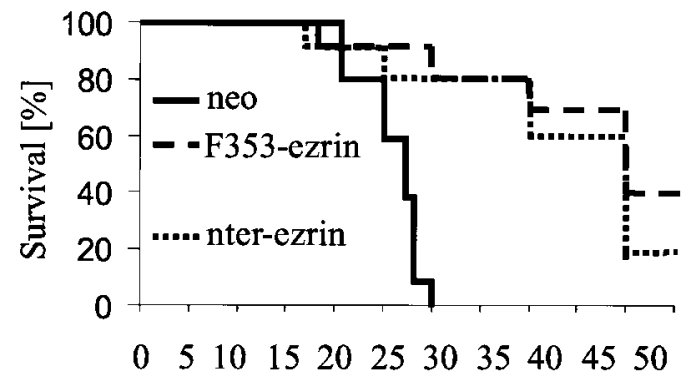

Time post implantation [days]

Figure 7. Expression of dominant-negative ezrins prolongs survival of U87MG human glioma xenograft-bearing athymic mice. U87MG neo, U87MG F353-ezrin, or U87MG nter-ezrin human glioma cells were implanted stereotactically into the striatum of athymic mice as detailed in Materials and Methods. $A$, Mice $(n=3)$ were killed when the first animal developed symptoms (at $28 \mathrm{~d}$ ). Brains were fixed, cut, and tumor volumes of hematoxylin-eosin-stained brains were determined with the MCID digitalization system ( ${ }^{*} p<0.05 ; n=3 ; t$ test). $B$, In an independent set of experiments, the animals of each group $(n=6)$ were observed at regular intervals until they developed neurological symptoms. Then the mice were killed.

published data that enhanced ezrin immunoreactivity in 115 glial tumors was correlated with increasing malignancy according to the World Health Organization classification of astrocytic tumors (Geiger et al., 2000). However, we showed that dominantnegative ezrin diminished colony formation that could not be rescued by $\mathrm{HGF}$ in vitro (Fig. $5 C$ ). Therefore, we postulate that one effect of dominant-negative ezrin in vivo is to inhibit the response to paracrine-autocrine $\mathrm{HGF}$.

In summary, we report that human malignant glioma cells engineered to express dominant-negative ezrin exhibit unaltered sensitivity toward apoptotic stimuli but diminished colony formation and a less migratory phenotype. Expression of the dominantnegative ezrins resulted in decreased expression of antiapoptotic BCL-2 family proteins and in decreased TGF- $\beta_{2}$ protein levels. These changes may be interrelated in that loss of BCL-2 may control the loss of TGF- $\beta_{2}$. The latter, in turn, is pivotal for glioma cell migration and is shown here also to mediate the promigratory effect of HGF in an ezrin-dependent manner. Thus, we have defined a novel signaling cascade for $\mathrm{HGF} / \mathrm{ezrin}$-induced migration that depends on BCL-2 and TGF- $\beta_{2}$, may involve various executing molecules, including $\alpha_{\mathrm{V}} \beta_{3}$ integrin and MMPs, and is critical for tumor growth in vivo.

\section{REFERENCES}

Algrain M, Turunen O, Vaheri A, Louvard D, Arpin M (1993) Ezrin contains cytoskeleton and membrane binding domains accounting for its proposed role as a membrane-cytoskeletal linker. J Cell Biol 120:129-139.

Belien A, Paganetti P, Schwab M (1999) Membrane-type matrix metalloprotease (MT1-MMP) enables invasive migration of glioma cells in central nervous system white matter. J Cell Biol 144:373-384.

Beviglia L, Kramer R (1999) HGF induces FAK activation and integrinmediated adhesion in MTLn3 breast carcinoma cells. Int $\mathrm{J}$ Cancer 83:640-649.

Bourguignon LY, Zhu H, Shao L, Chen YW (2000) CD44 interaction with c-Src kinase promotes cortactin-mediated cytoskeleton function and hyaluronic acid (HA)-dependent ovarian tumor cell migration. J Biol Chem: Nov 17, epub ahead of print.

Brooks P, Stromblad S, Sanders LC, von Schalscha TL, Aimes RT, Stetler-Stevenson WG, Quigley JP, Cheresh DA (1996) Localization of matrix metalloproteinase MMP-2 to the surface of invasive cells by interaction with integrin $\alpha_{\mathrm{V}} \beta_{3}$. Cell 85:683-693.

Chen H-C, Chan P-C, Tang M-J, Cheng C-H, Chang TJ (1998) Tyrosine phosphorylation of focal adhesion kinase stimulated by hepatocyte growth factor leads to mitogen-activated protein kinase activation. J Biol Chem 273:25777-25782.

Crepaldi T, Gautreau A, Comoglio P, Louvard D, Arpin M (1997) Ezrin is an effector of hepatocyte growth factor-mediated migration and morphogenesis in epithelial cells. J Cell Biol 138:423-434.

Deryugina E, Bourdon M, Luo G-X, Reisfeld R, Strongin A (1997) Matrix metalloproteinase-2 activation modulates glioma cell migration. J Cell Sci 110:2473-2482.

Deryugina E, Bourdon MA, Reisfeld RA, Strongin A (1998) Remodeling of collagen matrix by human tumor cells requires activation and cell surface association of matrix metalloproteinase-2. Cancer Res 58:3743-3750.

Furnari FB, Lin H, Huang HS, Cavenee WK (1997) Growth suppression of glioma cells by PTEN requires a functional phosphatase catalytic domain. Proc Natl Acad Sci USA 94:12479-12484.

Gautreau A, Poullet P, Louvard D, Arpin M (1999) Ezrin, a plasma membrane-microfilamente-linker, signals cell survival through the phosphatidylinositol 3-kinase/Akt pathway. Proc Natl Acad Sci USA 96:7300-7305.

Geiger KD, Stoldt P, Schlote W, Derouiche A (2000) Ezrin immunoreactivity is associated with increasing malignancy of astrocytic tumors but is absent in oligodendrogliomas. Am J Pathol 157:1785-1793.

Goldbrunner R, Bernstein J, Tonn J-C (1998) ECM-mediated glioma cell invasion. Microsc Res Tech 43:250-257.

Granés F, Urena JM, Rocamora N, Vilaró S (2000) Ezrin links syndecan-2 to the cytoskeleton. J Cell Sci 113:1267-1276.

Hiscox S, Jiang WG (1997) Regulation of endothelial CD44 expression and endothelium-tumour cell interactions by hepatocyte growth factor/ scatter factor. Biochem Biophys Res Commun 233:1-5.

Hiscox S, Jiang W (1999) Ezrin regulates cell-cell and cell-matrix adhesion, a possible role with E-cadherin/beta-catenin. J Cell Sci 112:3081-3090.

Ishii N, Maier D, Merlo A, Tada M, Sawamura Y, Diserens AC, Van Meir EG (1999) Frequent co-alterations of TP53, p16/CDKN2A, p14ARF, PTEN tumor suppressor genes in human glioma cell lines. Brain Pathol 9:469-479.

Kikkawa Y, Sanzen N, Fujiwara H, Sonnenberg A, Sekiguchi K (2000) Integrin binding specificity of laminin-10/11: laminin-10/11 are recognized by alpha 3 beta 1 , alpha 6 beta 1 and alpha 6 beta 4 integrins. J Cell Sci 113:869-876.

Lamszus K, Schmidt NO, Jin L, Laterra J, Zagzag D, Way D, Witte M, Weinand M, Goldberg ID, Westphal M, Rosen EM (1998) Scatter factor promotes motility of human glioma and neuromicrovascular endothelial cells. Int J Cancer 75:19-28.

Laterra J, Nam M, Rosen E, Rao JS, Lamszus K, Goldberg ID, Johnston $P$ (1997) Scatter factor/hepatocyte growth factor gene transfer enhances glioma growth and angiogenesis in vivo. Lab Invest 76:565-577.

Lesley J, Hyman R, Kincade PW (1993) CD44 and its interaction with extracellular matrix. Adv Immunol 54:271-335.

Lund-Johansen M, Bjerkvig R, Humphrey PA, Bigner SH, Bigner DD, Laerum OD (1990) Effect of epidermal growth factor on glioma cell growth, migration, and invasion in vitro. Cancer Res 50:6039-6044.

Merlo G, Cella N, Hynes N (1997) Apoptosis is accompanied by changes in bcl-2 and bax expression, induced by loss of attachment, and inhibited by specific extracellular matrix proteins in mammary epithelial cells. Cell Growth Differ 8:251-260.

Mohan P, Chintala SK, Mohanam S (1999) Adenovirus-mediated delivery of antisense gene to urokinase-type plasminogen activator receptor suppresses glioma invasion and tumor growth. Cancer Res 59:3369-3373.

Pedersen P, Marienhagen K, Mork S, Bjerkvig R (1993) Migratory pattern of fetal rat brain cells and human glioma cells in the adult rat brain. Cancer Res 53:5158-5165. 
Platten M, Wick W, Wild-Bode C, Aulwurm S, Dichgans J, Weller M (2000) Transforming growth factors beta1 (TGF- $\beta_{1}$ ) and TGF- $\beta_{2}$ promote glioma cell migration via up-regulation of $\alpha_{\mathrm{V}} \beta_{3}$ integrin expression. Biochem Biophys Res Commun 268:607-611.

Shofuda K, Moriyama K, Nishihashi A, Higashi S, Mizushima H, Yasumitsu H, Miki K, Sato H, Seiki M, Miyazaki K (1998) Role of tissue inhibitor of metalloproteinase-2 (TIMP-2) in regulation of pro-gelatinase A activation catalyzed by membrane-type matrix metalloproteinase-1 (MT1-MMP) in human cancer cells. J Biochem 124:462-470.

Ständer M, Naumann U, Dumitrescu L, Heneka M, Löschmann P, Gulbins E, Dichgans J, Weller M (1998) Decorin gene-transfer mediated suppression of TGF- $\beta$ synthesis abrogates experimental malignant glioma growth in vivo. Gene Therapy 5:1137-1144.

Trusolino L, Cavassa S, Angelini P, Ando M, Bertotti A, Comoglio PM, Boccaccio C (2000) HGF/scatter factor selectively promotes cell invasion by increasing integrin avidity. FASEB J 14:1629-1640.

Weller M, Frei K, Groscurth P, Krammer PH, Yonekawa Y (1994) Anti-Fas/APO-1 antibody-mediated apoptosis of cultured human glioma cells. Induction and modulation of sensitivity by cytokines. J Clin Invest 94:954-964.

Weller M, Malipiero U, Aguzzi A, Reed JC, Fontana A (1995) Protoon- cogene bcl-2 gene transfer abrogates Fas/APO-1 antibody-mediated apoptosis of human malignant glioma cells and confers resistance to chemotherapeutic drugs and therapeutic irradiation. J Clin Invest 95:2633-2643.

Weller M, Rieger J, Grimmel C, Van Meir EG, De Tribolet N, Krajewski S, Reed JC, von Deimling A, Dichgans J (1998) Predicting chemoresistance in human malignant glioma cells: the role of molecular genetic analysis. Int J Cancer 79:640-644.

Wick W, Wagner S, Kerkau S, Dichgans J, Tonn JC, Weller M (1998) BCL-2 promotes migration and invasiveness of human glioma cells. FEBS Lett 440:419-424.

Wick W, Grimmel C, Wagenknecht B, Dichgans J, Weller M (1999a) Betulinic acid-induced apoptosis in glioma cells: A sequential requirement for new protein synthesis, formation of reactive oxygen species, and caspase processing. J Pharmacol Exp Ther 289:1306-1312.

Wick W, Furnari F, Naumann U, Cavenee W, Weller M (1999b) PTEN gene transfer in human malignant glioma: sensitization to irradiation and CD95L-induced apoptosis. Oncogene 18:3936-3943.

Yonemura S, Tsukita S, Tsukita S (1999) Direct involvement of ezrin/ radixin/moesin (ERM)-binding membrane proteins in the organization of microvilli in collaboration with activated ERM proteins. J Cell Biol 145:1497-1509. 